\title{
Characteristics and Advantages of Flipped Class
}

\section{Yan-Mei SONG}

School of Foreign Languages, Nanyang Institute of Technology, Nanyang, Henan, China, 473004 songyanmei73@126.com

Keywords: Flipped Class, Characteristics, Advantages.

\begin{abstract}
This thesis explores the characteristics and advantages of flipped class according to the teaching experience and modern technology development. The main characteristics include Learning first, teaching second, the advanced way of "Ten into one", the micro class teaching way, self-responsible learning way. The advantages of flipped class have improving the students' schoolwork quality, enhancing students' learning motivation, being benefical to the close relationship between teachers and students, students learning more independently, improving the behaviors of students significantly, improving teachers' work satisfaction and bringing closer relationship between parents and school.

Under the traditional classroom teaching mode, the students study in the classroom and finish the homework after class. Flipped Class is not the same. Using this mode, the students will study micro teaching videos based on teaching objectives and content by themselves before class, complete advanced homework. In class, teachers and students finish the homework together, solve difficult problems, and create exploratory ways of learning. Flipped Class is not only the mode of "The first post-teaching”, but also the teaching mode of autonomy, interactivity and individuation. It is beneficial to enhance the quality of teaching and learning.
\end{abstract}

\section{The Characteristics of Flipped Class}

Definitely speaking, Salman Khan had no concept of Flipped Class when he taught his cousin math. He just wanted to provide one way which is easy to accept for his cousin and improved her study step by step. In fact, his video has been changing the whole education. Especially in 2007, Bergman and Aaron of Woodland Park High School recorded the PPT for teaching, and then uploaded video to the network to help the students make up missed lessons. The concept of Flipped Class became clear, and its significance is gradually accepted by people.

The characteristics of Flipped Class can be summarized as the following aspects:

"Learning first, teaching second" is the first characteristic of Flipped Class. Under the mode of Flipped Class, the students need to download and study the micro video recorded by the teacher before class, make notes and complete the advanced homework. Therefore, teachers and students can solve the confusions and problems that students meet during finishing their homework in class.

The second characteristic is that Flipped Class is different from "Learning first, teaching second" based on Guided Learning Plan. The teaching mode of "Learning first, teaching second" has been exploring in Primary and Secondary Schools in China. For example, Guided Learning Plan of Du Lang-kou is a typical case. However, with the development of science and technology, these teaching modes should be advanced in accordance with the principle of "Learning first, teaching second". There are three differences between "Learning first, teaching second" based on micro videos and Guided Learning Plan. First of all, it is the vivid interpretation. The teacher can teach the students more vividly in the video, so it is certainly more favored by students than the mode of Guided Learning Plan. Second, the feedback is timely. No matter the feedback is before the class or in this process; they can be settled more timely and quickly under the background of network. It can also save a lot of time when the teacher correcting homework. The third, it is easy to save and retrieve. Electronic data is easier for students to review than Guided Learning Plan, and it is easy to save and retrieve for the school.

The third characteristic is the advanced way of "Ten into one". With the support of modern information technology, students can complete the homework after learning the micro video to 
ensure that they have mastered the knowledge explained in this video. Only when the homework is all done and has no mistake, the student is allowed to enter the next phase of the video learning. If the homework has errors, the student will need to continue watching the video or ask for online help according to relevant tips. Until the student has mastered the knowledge points, finished advanced homework, he can enter the next phase of the video learning. After finishing knowledge learning of one unit, the student needs to take exams to the corresponding unit. Only the unit test achieves the master degree, the student is allowed to study the next unit. In the mode of "ten into one", the student can master the knowledge of each unit as long as time permits and has effective targeted tutoring. Finally, most of the students in the class can master the knowledge expertly.

The fourth characteristic is the micro class teaching way. According to the teaching objectives and teaching content, teachers can make teaching video and design advanced homework. The interpretation of these micro videos is vivid and clear. And every video focuses on a knowledge point, making the knowledge clearer. And it often takes 5 to 8 minutes, so the students can concentrate before students are tired of listening. And unlike the previous network classroom, the interpretation of micro video is given priority to the analysis of knowledge and based on students' learning ability. In the video, teachers will not appear, and it is not the reproduction of classroom scene. These factors that may distract students' attention are excluded. When the teachers are recording the micro video, they assume that their teaching object is one student; they are making explanation and analysis for a student. This is about to change the character of teachers from the previous "lecturer" into "coach", from "the sage of the platform" to "counselor". In the class of Massive Open Online Courses and Flipped Class, teachers' performance is not so highlight, but the role of teachers is more important. Just like Salman khan saying: I do not stand on the platform for lectures, it makes people feel sweet, just like we are sitting in front of a table, studying together, and write the content on a piece of paper.

The fifth characteristic is self-responsible learning way. Students are responsible for their own study, rather than the teachers or parents. Only when they know their learning goals, make efforts and exploration, they are able to prove that they have reached the requirements of the target. And it is the true positive learning and autonomous learning. In the mode of Flipped Class, the students study video before class under the guidance of teachers, communicate study achievement and participate in the discussion individually or in the form of group work in class. Teachers inspect students' learning situation, ask questions and solve problems. Aaron from Woodland Park High School once said that each student has something to do. It may look a little messy, students are no longer so quiet, but each student is actively into real learning.

\section{The Advantages of Flipped Class}

The practice of Massive Open Online Courses and Flipped Class at home and aboard shows that this teaching mode has several outstanding advantages.

First, it is beneficial to improve the students' schoolwork quality. Woodland Park High School, Clinton Dale High School and Byron High School are the main origins of Flipped Class. Flipped Class is paid more attention, because this model has been improving students' scholastic attainment. The proportion of students who passed math test in Byron High School increased from 29.9\% in 2006 to $73.8 \%$ in 2011. At the same time, the average math scores of ACT improved from 21.2 to 24.5. And Byron High School won the "Distinguished School Award" of INTEL in 2011 because of its performance in math, and got more educational funds. From 2010, the rate of make-up examinees of Clinton Dale High School has down to 19\% from 52\%, mathematics rate of make-up examinees declined from $44 \%$ to $13 \%$, the science declined from $41 \%$ to $19 \%$.

Second, it is helpful to enhance students' learning motivation. The teachers working in Flipped Class think that the mode allows students to study in advance and the learning process is independent, and they can discuss with other students. More importantly, students have more opportunities to participate and perform. Therefore, students showed high participation before class and in the class, which improved students' interest and motivation in learning. Compared with the traditional teaching mode, they prefer Flipped Class. 
The third, the relationship between teachers and students is closer than before. Flipped Class does not cancel the classroom, or replacing teachers with video learning. It is a kind of mixed learning mode combining online learning and classroom learning. It asks more for teacher's subject quality and educational qualities. Many teachers said that, compared with the traditional pattern, Flipped Class can make teachers have more time to communicate with students one-to-one, they can know more about students. It makes interaction between teachers and students, students and students more meaningful. Thus, it did a good job in improving the relationship between teachers and students.

Carolyn Durley, a Canadian teacher, said the reason why she carried out Flipped Class and Massive Open Online Courses is that she did not want to lose the close and friendly relationship with students. Dolly said: "I get more opportunity to have meaningful conversation with each student now (there are 30 students). The relationship between us becomes friendlier because we have more interactive and meaningful conversation. I also want to do this before, but I don't have the time". The survey of Flipped Class Learning Websites also showed that "Flipped Class raised the quality and quantity of communicating with students".

The fourth, students learn more independently. The most important goal of Flipped Class is to let students learn more independently and take responsibility for their own learning. The enhancement of students' autonomous learning ability is embodied in the following three aspects. Students must make clear of their learning targets. In order to reach the goal, it is the positive performance to study hard, whether video or other materials learning, finish the homework, and seek help from others. It is necessary to prove that they reach the goal in the proper way. If students can make some improvements in these three aspects, the ability of autonomous learning is of course improved.

The mathematical teachers of National University of Singapore Affiliated High School said that there are three main benefits to implement Flipped Class and Massive Open Online Courses. One is that Flipped Class can let the students study according to each progress. The second one is that Massive Open Online Course is a very good review tool, especially for the final exam, for students can freely learn the lessons of the past. The third one is that students can use knowledge more flexibly.

Of course, as Canadian teachers talked, students can not adapt this way of teaching quickly in the beginning. Because students are used to studying under the control of the teacher, they do not have the habit of independent learning. It also needs a certain process for students to adapt to this way of study. Some students can adapt this way of study in a month, some students need more time.

The fifth, the behaviors of students have improved significantly. In some middle school, students' behavior has improved after carried out Flipped Class and Massive Open Online Courses, such as Clinton Dale High School. Clinton Dale High School began to implement Flipped Class from 2010, and the disciplinary offence declined from 736 in 2009 to 249 in 2010. In 2011, it reduced to 187. In two years, decreased by 74\%. Complaints from parents were down from 200 to7. Therefore, the principal decided to carry out Flipped Class and Massive Open Online Courses in the fall of 2011. The practice of Woodland Park High School also confirmed that. The teachers said that students could make hands-on practice or had activities within the team in the classroom and they all had things to do. Thus, Flipped Class has improved the classroom management.

The sixth, teachers' work satisfaction improved. In 2012, Flipped Class learning websites in the United States made a survey of 453 teachers engaged in Flipped Class and Massive Open Online Courses. The survey showed that $88 \%$ of the teachers teaching satisfaction has been improved, $46 \%$ of the teachers have significantly increased in the implementation of Flipped Class and Massive Open Online Courses. 99\% of the teachers answered that they would continue to use this mode next year. As teachers who were surveyed said: "the more flipping we have, the more we want to flip". Dolly, a Canadian teacher believes that the interpretation of video reduces the repetition rate and it is helpful to overcome the teachers' job burnout.

The seventh, the relationship between parents and school is more closely. Under the mode of Flipped Class, the students finish the video learning mostly at home. In this way, parents can know more about the overall learning situation of students. Sometimes, parents and students learn and discuss the video together. Existing practice shows that the parents support the learning mode in 
general. The principal of Clinton Dell High School, Greg Green said: "We are not only in the education of our students, we are also in the education of our community". "Student learn video before class, finish the homework and discussion in class. Parents can directly know more about children's learning in school, also give parents the opportunity to participate in student education. And parents also like to watch video on the Internet with children, when children meet difficulties, parents can give effectively help". In Okanagan Mission Secondary School, the parents said: "it is good to see children out of confusion, and teach themselves". Tom Curle' survey also showed that $80 \%$ of the students think the relationship between students and students, students and teachers is more closely and positive; $90 \%$ of the teachers think that the relationship between teachers and students have a positive improvement.

\section{References}

[1] Aaron Sams and Jonathan Bergmann. Flip Your Students' Learning. Educational Leadership, 70(6), 1620, 2013.

[2] Brenda Alvarez. Flipping the classroom: Homework in Class, Lessons at home. Education Digest. 77(13), 18-22, 2012.

[3] Classroomwindow. What do teachers who've flipped their classroom have to report?. http:/flipped learning. org/cms/libo7/VA01923112/centricity/Domain/41/classroom window infographic 7-12.

[4] Janets Teffenhagen. Flipped classrooms create magic and controversy in B.C. schools.VancouverSun.http://www. Vancouversun.Com/news/Flipped+classrooms+create+magic+co ntroversy+schools/ 7202690/story. Html, 2012-09-06.

org/cms/libo7/VA01923112/centricity/Domain/41/classroom window infographic 7-12. 